\title{
Country asymmetries, endogenous product choice and the timing of trade liberalization
}

\author{
Antonio Cabrales ${ }^{\mathrm{a}, *}$, Massimo Motta ${ }^{\mathrm{a}, \mathrm{b}}$ \\ ${ }^{a}$ Department of Economics, Universitat Pompeu Fabra, Ramon Trias Fargas 25-27, \\ E-08005 Barcelona, Spain \\ ${ }^{\mathrm{b}}$ European University Institute, Badia Fiesolana, Via dei Roccettini 9, \\ I-50016 San Domenico di Fiesole (FI), Italy
}

Received 1 July 1998; accepted 2 December 1999

\begin{abstract}
We analyze the effects of trade liberalization on firms' decisions and profits in a vertical product differentiation model with countries which have different characteristics. Firms decide product specifications at the beginning of the game, in which autarky is followed by trade liberalization (whose date is anticipated). Our analysis suggests that a firm located in a large (or rich) country is the likely market leader at the trade equilibrium. This outcome might be reversed if small country firms have a strong cost advantage, transport costs are negligible, or if the large country opens its market before the small one. (C) 2001 Elsevier Science B.V. All rights reserved.
\end{abstract}

JEL classification: F12; F15

Keywords: Trade liberalization; Product differentiation; International trade

\section{Introduction}

This paper analyzes oligopolistic competition between firms located in two countries having different sizes. It aims at uncovering the effects of trade

* Corresponding author. Tel.: + 34-93-5422765; fax: + 34-93-5421746.

E-mail address: antonio.cabrales@econ.upf.es (A. Cabrales). 
liberalization on product choice and profits obtained by the firms, and total welfare of the countries involved.

We assume that firms correctly anticipate the pace of trade liberalization and take it into account when deciding their product specifications at the beginning of the game. For a certain number of periods each country is in autarky. Then trade liberalization occurs, and firms compete in the international market for the rest of the time the game is played. The intertemporal profits of the firms are therefore a function of the time at which trade liberalization occurs. The longer the delay with which countries decide to open their borders, the larger the impact of the autarky conditions and therefore the more relevant the characteristic of the domestic market. In such a setting, autarky and international trade are special cases of a more general situation. This is a noteworthy feature of our model, since most models of trade do not deal with intermediate situations where firms operate under autarky in some periods and under trade in others. The crucial parameter here is the timing of trade liberalization. Although we treat this parameter as exogenous and analyze the effects of changes in it, our framework might be extended to analyze the case where the timing of trade reform can be an endogenous variable.

To study endogenous product choices, we use a partial equilibrium model of vertical product differentiation. We show that a firm from a large (or rich) country is likely to be the industry leader after trade liberalization. Indeed, the equilibrium where the market leader is a firm from a small (or poor) country either does not exist (when asymmetries are strong), or if it exists it is riskdominated by the equilibrium where the market leader comes from the large (or rich) country. In a version of the model with production cost asymmetries, the small country will become the market leader if it has a strong production cost advantage.

The opening of trade has two effects on the firms' profits. On the one side, there is a competition effect, since firms face new foreign competitors. On the other side, there is a market expansion effect, since with trade liberalization firms can sell in an additional market. In general the market leader, which is more likely to be the firm from the large country, tends to gain more from free trade. The firm from the small country might still benefit from trade even if it is not the market leader, because it can sell in a larger market than the domestic one. This happens when the asymmetry in size between the countries is very pronounced. For the same reason, when trade occurs with a small enough country, the large country's firm will lose from trade even though it is the market leader at the trade equilibrium (the competition effect dominates the size effect).

Our analysis helps to understand better the literature on gains from trade and their distribution between unequal countries. Markusen (1981) shows that trade does not necessarily increase income in both countries, if they differ in size. In his model firms (one in each country) produce homogeneous goods and compete à la Cournot when trade opens. Under constant returns to scale the large 
country would be an importer of the good and might lose relative to autarky. The small country is therefore the most likely to benefit from trade liberalization. The situation can change under increasing returns to scale, since the large country would have a cost advantage which might result in it being the exporter and the beneficiary of trade. With monopolistic competition, Krugman (1980) shows that workers are better off in the larger country, owing to the role played by economies of scale. However, trade has a positive impact on both countries' welfare, since consumers benefit from larger number of product varieties.

In our model, similarly to Krugman (1980), welfare is highest in both countries when trade liberalization occurs immediately. Possible losses by firms are outweighed by consumers' gains, which come under the form of lower prices and higher average qualities. In a sense, however, we find again Markusen's concern that trade brings about unequal gains. Despite the overall increase in welfare for both the large and the small country, our analysis underlines the possible detrimental impact that trade can have on the profitability of the firms located in one of the countries. This is an issue which has received less attention in the trade literature, even though it is crucial to understand under which conditions firms have an incentive to support trade processes.

A paper by Anderson et al. (1989) addresses this question in the context of an oligopolistic industry with homogeneous goods. It is found there that at least in one of the two countries firms make higher profits under autarky than under free trade. In our model, unlike Anderson et al. (1989), it is not always the large country firms which lose from trade. ${ }^{1}$ Our fixed costs of quality improvements imply that the firm located in the bigger market has an advantage (comparable to the cost advantage enjoyed in a model with increasing returns to scale) which makes it the likely high-quality producer when markets open. A firm in the small country can then be relegated to low-quality products and lose from trade. ${ }^{2}$

In our model an immediate move towards free trade allows both countries to improve their welfare with respect to autarky. However, our analysis also suggests that trade liberalization reforms might receive strong opposition from industrial groups, whenever firms' profitability is lower under trade.

This paper is also related to our previous work. Motta et al. (1997) presented a similar model and found that domestic market demand plays an important role in explaining which firms are likely to be the leaders in international markets, a result in line with both the trade literature (see Linder, 1961; Krugman, 1980; Dinopoulos, 1988) and the business literature (see, for instance, Porter, 1990). In that paper, however, firms did not anticipate the occurrence of

\footnotetext{
${ }^{1}$ Large countries might lose from trade also in Cordella (1993) and Nguyen and Wigle (1992).

${ }^{2}$ This is an aspect which was also shown in a different context by Motta (1992), where firms from the small country might have to exit the market because of the competition by higher quality producers.
} 
trade and could only adjust their quality choices after unforeseen trade liberalization had been announced. Here, instead, we deal with perfectly rational agents which fully anticipate the process of trade liberalization and take it into account when making their product choices. Another important difference is that our previous paper did not analyze how trade affects firms' profitability, a question central to the present article. ${ }^{3}$ Further, in the present paper we study the sensitivity of the results with respect to a number of variables we had not considered in our previous paper. In particular, we analyze here the role played by transportation costs, as well as differences in technologies and in production costs between the two countries.

Cabrales et al. (2000) analyze a laboratory experiment on a game which is similar to the one in this paper and find that the equilibrium which corresponds to the case of the leader coming from the large country is selected much more often by the experimental subjects than the alternative equilibrium. Therefore, the laboratory results support the predictive power of risk dominance as a criterion of equilibrium selection, as used in the present paper.

The paper is presented in the following way. In Section 2, we present the general features of the game. This basic model is then studied within a simple vertical product differentiation framework in Section 3. Some extensions are considered in Section 4. Section 5 concludes the paper.

\section{The basic model}

Country A, which we call the large country, has a share $\mu \geq \frac{1}{2}$ of the total population size $S$ of the world. Country B's share of the world population is $1-\mu$. Apart from this size asymmetry, and unless otherwise specified, these two countries are perfectly identical.

At the beginning of the game, two firms are considering entry into the industry we want to analyze. One firm is located in country A, and the other in country B. The firms are new in the industry and they have to decide the specification of their product. They then incur the cost of their investment in product specification and cannot change it any longer. Product choice is therefore endogenous and irreversible. ${ }^{4}$

Firms anticipate future events correctly. In particular, they know that the two countries have negotiated a trade liberalization agreement. For a number $K$ of years, from time 0 to time $K-1$, the two markets will operate under a regime of

\footnotetext{
${ }^{3} \mathrm{~A}$ crucial variable for this question is the relative market size of the countries. Since Motta et al. (1997) assumed identical market sizes, the study of the effects of trade on firms' profits would have been uninteresting there.
}

${ }^{4}$ See Motta et al. (1997) for the case where firms are already established when the game starts. 
autarky. Starting from period $K$, however, the two markets will be completely integrated and they will remain in a such a situation until the end of the game, ${ }^{5}$ which occurs at time $T-1 .^{6}$

Firms have a common discount factor, $d$ (we may think that capital markets are open and therefore interest rates equalize), and the total present value of profits of firm $i$ is

$$
V_{i}=\sum_{t=0}^{K-1} d^{t} \Pi_{i}^{\mathrm{M}}\left(x_{i}\right)+\sum_{t=K}^{T-1} d^{t} \Pi_{i}^{\mathrm{D}}\left(x_{i}, x_{j}\right)-G_{i}\left(x_{i}\right),
$$

where $\Pi_{i}^{\mathrm{M}}$ represents the monopoly profit of firm $i$ (i.e. the per-period profit when trade is not open) and $\Pi_{i}^{\mathrm{D}}$ the duopoly profit. ${ }^{7}$ The variable which denotes the investment in product specification is $x_{i}$. Note that in monopoly the profits of firm $i$ are independent of the product chosen by firm $j$. $G$ is a function which attributes a cost to the investment made into the variety of the good. We assume that firms share the same technology and that no other fixed costs are necessary to provide a market.

The above expression can be written as

$$
V_{i}=\frac{\left(1-d^{K}\right)}{(1-d)} \Pi_{i}^{\mathrm{M}}+\frac{\left(d^{K}-d^{T}\right)}{(1-d)} \Pi_{i}^{\mathrm{D}}-G
$$

or, equivalently,

$$
\frac{(1-d)}{\left(1-d^{T}\right)} V_{i}=\frac{\left(1-d^{K}\right)}{\left(1-d^{T}\right)} \Pi_{i}^{\mathrm{M}}+\frac{\left(d^{K}-d^{T}\right)}{\left(1-d^{T}\right)} \Pi_{i}^{\mathrm{D}}-\frac{(1-d)}{\left(1-d^{T}\right)} G
$$

With an appropriate transformation of variables $\phi=\left(1-d^{K}\right) /\left(1-d^{T}\right)$ we obtain

$$
\pi_{i}=\phi \Pi_{i}^{\mathrm{M}}+(1-\phi) \Pi_{i}^{\mathrm{D}}-F,
$$

where $F=\left[(1-d) /\left(1-d^{T}\right)\right] G$. Note that $\phi$ tends to zero as $K$ tends to zero. In this case, trade liberalization is immediate and autarky profits $\Pi_{i}^{\mathrm{M}}$ do not play any role in the firm's present value of profits. At the other extreme, when $\phi$ is equal to one, $K$ tends to $T-1$. Firms are in a situation of domestic monopoly throughout their life.

\footnotetext{
${ }^{5}$ Introducing a period of progressive adjustment to complete liberalization of trade would complicate the analysis without adding any particular element of interest.

${ }^{6} T$ can be either finite or infinite. By assuming the latter, though, we would have a supergame which gives rise to many possible equilibria. Under finite horizon, we avoid this problem.

${ }^{7}$ Profits depend also on prices and quantities. Monopoly profits do not depend on the other country's investment, while duopoly profits depend on both countries' investments.
} 


\section{Endogenous quality choices: The model}

We use a vertical product differentiation $\operatorname{model}^{8}$ to analyze more in depth the game whose general features we have briefly outlined above. In this section we assume that there exist no transport costs and that technology, costs and incomes (or tastes) are identical in the two countries. (We relax each of these assumptions in the next section.) Countries differ only by population sizes.

In the two countries consumers have utility function $U=\theta u-p$, if they buy one unit of the differentiated good, and $U=0$, if they do not buy. The symbols $u$ and $p$ denote quality and price of the good, while $\theta$ represents a taste parameter. The distribution of $\theta$ in the two countries is the same. We assume it is uniform and that $\theta \in[0, \bar{\theta}]$. The mass of consumers is given by $\bar{\theta} S_{i}$ in each country $i(i=\mathrm{A}, \mathrm{B})$, with $S_{\mathrm{A}} \geq S_{\mathrm{B}}$ (country A has a higher population size than country B).

Firms decide on the quality they want to produce at the initial period $t=0$. To do so, they incur a fixed cost $F_{i}=k u_{i}^{2} / 2 .{ }^{9}$ Firms choose prices in each period $t .{ }^{10}$ We can now solve for the last stage of the game. In the case of monopoly, a firm faces demand $q_{i}=S_{i} \bar{\theta}-p_{i} / u_{i}$, and its optimal price choice is $p_{i}=u_{i} \bar{\theta} / 2$. Correspondingly, the monopolist profit is $\Pi_{i}^{\mathrm{M}}=u_{i} S_{i} \bar{\theta}^{2} / 4$. Note that the higher the population size, the higher the marginal profitability of the monopolist, which has a larger incentive to invest in quality. In the case of duopoly, that is, when firms compete in the international market, demand faced by the top and bottom quality firm, respectively, would be $q_{1}=\bar{\theta}-\left(p_{1}-p_{2}\right) /\left(u_{1}-u_{2}\right)$ and $q_{2}=\left(p_{1}-p_{2}\right) /\left(u_{1}-u_{2}\right)-p_{2} / u_{2}$, where $u_{1}>u_{2}$.

At the price equilibrium, profits for the top and bottom quality are: ${ }^{11}$

$$
\Pi_{1}^{\mathrm{D}}=\frac{4 u_{1}^{2}\left(u_{1}-u_{2}\right) S \bar{\theta}^{2}}{\left(4 u_{1}-u_{2}\right)^{2}}, \quad \Pi_{2}^{\mathrm{D}}=\frac{u_{1} u_{2}\left(u_{1}-u_{2}\right) S \bar{\theta}^{2}}{\left(4 u_{1}-u_{2}\right)^{2}} .
$$

We are now able to write the intertemporal profit functions of the firms:

$$
\pi_{1 j}=\frac{\phi S_{j} u_{1} \bar{\theta}^{2}}{4}+\frac{4(1-\phi) u_{1}^{2}\left(u_{1}-u_{2}\right) S \bar{\theta}^{2}}{\left(4 u_{1}-u_{2}\right)^{2}}-\frac{k u_{1}^{2}}{2},
$$

\footnotetext{
${ }^{8}$ See e.g. Gabszewicz and Thisse (1979), Shaked and Sutton (1982), and Motta (1993).

${ }^{9}$ This function is widely used in this type of models. See, e.g., Motta (1993). One may interpret the parameter $k$ as incorporating the scalar term $(1-d) /\left(1-d^{T}\right)$ in Eq. (3).

${ }^{10}$ In the working paper version we show that the qualitative results are unaffected by the assumption of quantity instead of price competition.

${ }^{11}$ One can check that the prices chosen at the last stage of the game by the firms are independent of the hypothesis of integrated vs. segmented markets, that is of whether firms can price discriminate or not across countries.
} 


$$
\begin{gathered}
\pi_{2 i}=\frac{\phi S_{i} u_{2} \bar{\theta}^{2}}{4}+\frac{(1-\phi) u_{1} u_{2}\left(u_{1}-u_{2}\right) S \bar{\theta}^{2}}{\left(4 u_{1}-u_{2}\right)^{2}}-\frac{k u_{2}^{2}}{2}, \\
i, j=\mathrm{A}, \mathrm{B}, \quad i \neq j .
\end{gathered}
$$

Recall that in the equation above $S_{\mathrm{A}}=\mu S$ and that $S_{\mathrm{B}}=(1-\mu) S$. We have deliberately not specified whether the high (low)-quality firm is located in country A or in country B. Indeed, there might exist two equilibria in pure strategies. In the first one, it is the firm located in the bigger country which produces the top quality. In the second, the market leader is the firm located in the small country.

\subsection{The market leader is located in the big country}

If the top quality firm comes from country A, the first-order conditions are:

$$
\begin{aligned}
& S \bar{\theta}^{2}\left\{\left[64 u_{1}^{3}(1-\phi+\mu \phi)-48 u_{1}^{2} u_{2}(1-\phi+\mu \phi)+u_{1} u_{2}^{2}(32-32 \phi\right.\right. \\
& \left.\left.\quad+12 \mu \phi)-\mu \phi u_{2}^{3}\right] /\left[4\left(4 u_{1}-u_{2}\right)^{3}\right]\right\}=k u_{1}, \\
& S \bar{\theta}^{2}\left\{\left[16 u_{1}^{3}(1+3 \phi-4 \mu \phi)-u_{1}^{2} u_{2}(28+20 \phi-48 \mu \phi)\right.\right. \\
& \left.\left.\quad+12 \phi u_{1} u_{2}^{2}(1-\mu)-\phi u_{2}^{3}(1-\mu)\right] /\left[4\left(4 u_{1}-u_{2}\right)^{3}\right]\right\}=k u_{2} .
\end{aligned}
$$

Divide these two equations, rearrange and write $u_{1}=r u_{2}$ with $r>1$ to obtain

$$
\begin{aligned}
& S \bar{\theta}^{2} u_{2}\left\{\left[16 r^{4}(4 \mu \phi-3 \phi-1)+r^{3}(16 \mu \phi-44 \phi+92)\right.\right. \\
& \quad-r^{2}(36 \mu \phi-36 \phi+48)+r(11 \mu \phi-31 \phi+32) \\
& \left.\quad+\mu \phi] /\left[4(4 r-1)^{3}\right]\right\}=0 .
\end{aligned}
$$

We have found the analytical solutions of this equation by using the program Mathematica. There is only one real root $r^{*}=r(\mu, \phi)$ which satisfies the constraint $r>1$. By substituting $r^{*}$ into expression (8) and using $u_{1}=r u_{2}$ we find the two qualities $\left(u_{1}^{*}, u_{2}^{*}\right)$. Note that the parameters $S, \bar{\theta}^{2}, 1 / k$ enter the expressions in a multiplicative way and therefore do not affect the solutions. From now on we normalize these values to $S=1, \bar{\theta}=10$, and $k=1$. This is without loss of generality, as the same property holds for the equilibrium with the firm from the small country being the leader.

For the pair $\left(u_{1}^{*}, u_{2}^{*}\right)$ to be an equilibrium, we also have to check that country B firm does not find it profitable to 'leapfrog' the rival and provide a quality higher than $u_{1}^{*}$. In other words, it must be checked that there exists no quality $u_{1}^{\prime}$ such that $\pi_{1}\left(u_{1}^{\prime}, u_{2}=u_{1}^{*}\right) \geq \pi_{2}^{*}\left(u_{1}^{*}, u_{2}^{*}\right)$. Likewise, it must be checked that the firm from country A does not have an incentive to deviate by supplying a quality which is lower than $u_{2}^{*}$. Indeed, it is possible to prove that these deviations 
are not profitable, and therefore conclude that the pair $\left(u_{1}^{*}, u_{2}^{*}\right)$ is always an equilibrium. ${ }^{12}$

By replacing the equilibrium qualities one can obtain the expressions for equilibrium profits, consumer surplus, domestic welfare and aggregate welfare. ${ }^{13}$

Fig. 1 shows equilibrium qualities, profits and welfares as functions of the delay in trade liberalization, represented by the parameter $\phi$, which ranges from 0 (free trade from the first period) to 1 (autarky forever). Each curve is drawn for a given value of the parameter $\mu$, which denotes the relative size of the large market. If a change of $\phi$ is represented by a movement along a given curve, a change in $\mu$ shifts the curve. The top panels illustrate the evolution of equilibrium qualities. As for $u_{1}$, the results are unambiguous. For any given relative market size, earlier liberalization increases the value of the top quality. Indeed, a lower value of $\phi$ has two effects which have the same sign. Firstly, trade increases the size of the market (market size effect) and thus the marginal profitability of quality investment. Secondly, it also increases the period in which the firm is exposed to competition (competition effect). In turn, this pushes the firm to increase its product quality to differentiate it from the other firm. Both effects raise the incentives to provide a higher quality. For a given date of trade liberalization, an increase in the relative size of country A (an increase in parameter $\mu$ ) increases the marginal profitability of quality, and thus the incentive to invest in quality improvement.

The behavior of the bottom quality, apparently less clear cut, can be understood by taking into account that (for given size of the market) the need to differentiate in order to relax price competition pushes the low-quality firm to decrease its quality level. The competition effect takes in this case an opposite sign to the market size effect. The opening of trade tends to decrease the quality produced by the former firm. When country B is not too small (e.g. when $\mu=0.5$ or 0.7 ), the market size effect - which in principle would tend to increase qualities by both firms - is less important. Hence, liberalization decreases the quality level of the firm located in the small country. However, when country $\mathrm{B}$ is very small (e.g. when it is only a tenth of the total population size, $\mu=0.9$ ), the positive effect due to the expansion of the market which follows trade liberalization is stronger than the competition effect, thus increasing $u_{2}$ as $\phi$ decreases.

The interpretation of the equilibrium profit schedules for a given size but different liberalization dates goes along the same lines. The top quality firm is the one which reaps the benefit from liberalization to a greater extent. However,

\footnotetext{
${ }^{12}$ Details are available from the authors upon request.

${ }^{13} \mathrm{We}$ omit the analytical solutions because they are extremely long and little can be gained from their inspection.
} 

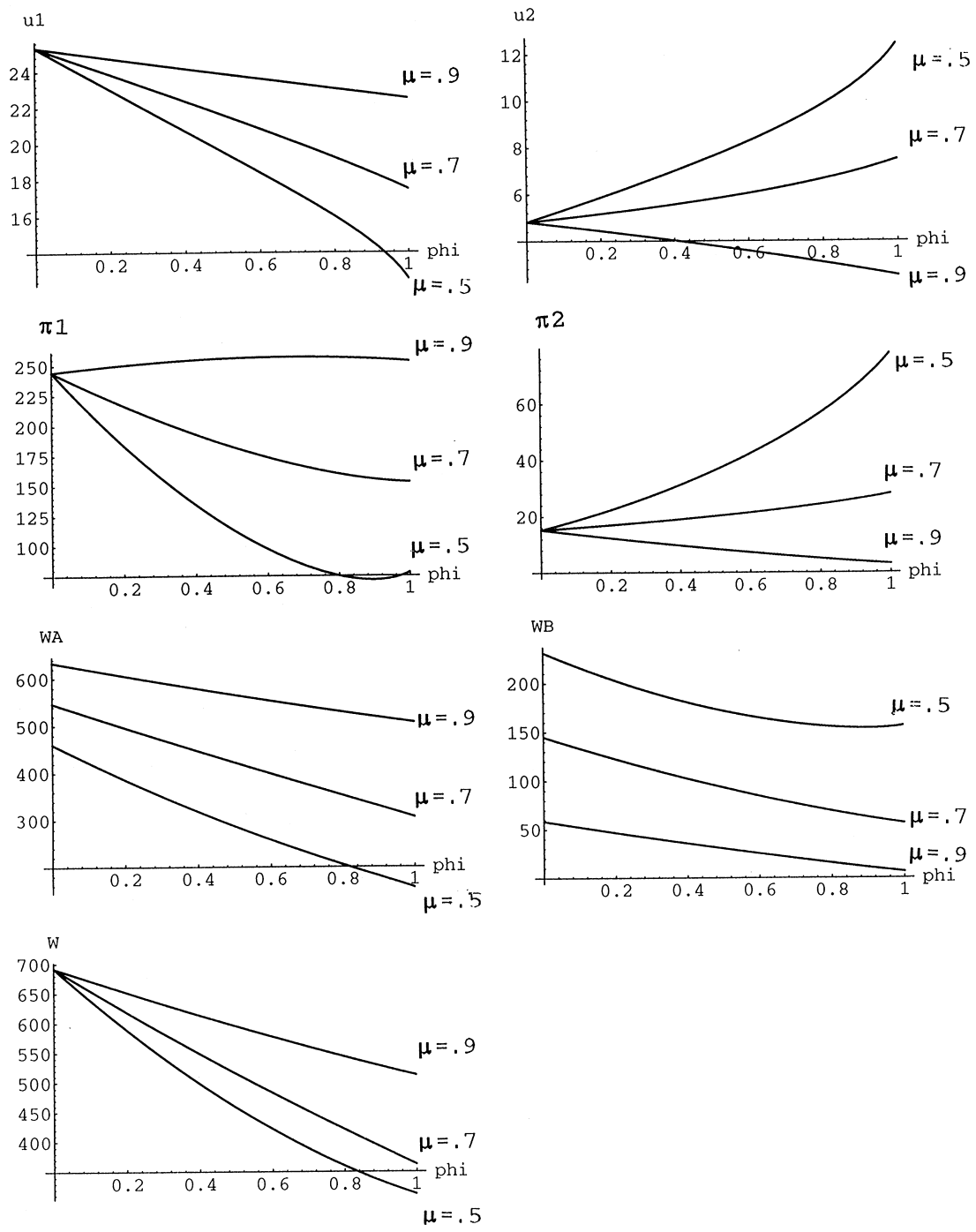

Fig. 1. Market leader in the large country. Equilibrium qualities, profits and welfares. $\phi=$ timing of trade liberalization; $\phi=0$, immediate liberalization; $\phi=1$, autarky forever.

when country A is very large, the expansion of the market given by trade tends to play a smaller role than the effect of competition. (In the limit, when the size of the small country tends to zero, the firm would have to compete with a rival on a market of the same size as in autarky.) For any given timing of liberalization, 
an increase in the value of $\mu$ increases market demand and therefore the profitability of country A firm, whose profit function shifts upwards. Obviously, profit shifts downwards for the bottom quality firm, since an increase in $\mu$ implies a decrease in domestic demand.

Consumers from both countries benefit from earlier liberalization (lower $\phi$ ) through an increased competition which tends to increase the availability of varieties, to reduce prices for given qualities and to increase the level of the top quality on the market. The positive effect on consumer utility tends to outweigh the possible negative effect on firm profits. Immediate trade liberalization brings about a higher welfare level than under autarky, and for both countries. ${ }^{14}$ However, there is at least one firm that loses by liberalizing trade early, so one could expect that this firm will oppose liberalization, if no compensating mechanism is implemented.

\subsection{The market leader is located in the small country}

If the top quality firm is located in country $\mathrm{B}$, the first-order conditions are

$$
\begin{aligned}
& S \bar{\theta}^{2}\left\{\left[64 u_{1}^{3}(1-\mu \phi)-48 u_{1}^{2} u_{2}(1-\mu \phi)+u_{1} u_{2}^{2}(32-20 \phi-12 \mu \phi)\right.\right. \\
& \left.\left.\quad-u_{2}^{3}(\phi-\mu \phi)\right] /\left[4\left(4 u_{1}-u_{2}\right)^{3}\right]\right\}=k u_{1}, \\
& S \bar{\theta}^{2}\left\{\left[16 u_{1}^{3}(1-\phi+4 \mu \phi)-u_{1}^{2} u_{2}(28-28 \phi+48 \mu \phi)+12 \mu \phi u_{1} u_{2}^{2}\right.\right. \\
& \left.\left.\quad-\mu \phi u_{2}^{3}\right] /\left[4\left(4 u_{1}-u_{2}\right)^{3}\right]\right\}=k u_{2} .
\end{aligned}
$$

We can then write $u_{1}=z u_{2}$ (with $z \geq 1$ ) and use the same procedure followed to derive the equilibrium solutions in the previous section. We then find the value $z^{*}=z(\mu, \phi)$ which satisfies the first-order conditions, and by substitution the candidate solution $\left(u_{1}^{* *}, u_{2}^{* *}\right)$. However, this is not always an equilibrium. Unless the two countries have exactly the same size, it is always possible to find a value of the parameter $\phi$ large enough for the candidate equilibrium to break down. ${ }^{15}$ The firm located in the large country finds it profitable to produce a quality $u_{1}^{\prime}$ higher than the quality $u_{1}^{* *}$ the rival would produce at the candidate solution, as $\pi_{1}^{\prime}\left(u_{1}^{\prime}, u_{2}=u_{1}^{* *}\right)>\pi_{2}^{* *}\left(u_{1}^{* *}, u_{2}^{* *}\right)$. The smaller the size of country B, the more difficult it will be for its firm to be the market leader (the lower the

\footnotetext{
${ }^{14}$ However, if trade does not open immediately but after many periods of autarky a country's welfare might worsen with respect to the closed economy equilibrium. This occurs when two countries are very similar and trade is open for few periods only. In this case the firm which is going to produce the lower quality at equilibrium has lower profits than under monopoly, and trade is not open long enough for consumers' gains to offset the firm's losses (in Fig. 1, the welfare schedule $W_{\mathrm{B}}$ for $\mu=0.5$ takes a U-shape).

${ }^{15}$ See the working paper version of this paper for more details.
} 
value of $\phi$ which is necessary to sustain this equilibrium). In the case where $\phi=0$ each firm is selling on the single market from the very beginning, and thus the reduced size of the domestic market does not limit the scope for the investment. However, as the delay in trade integration increases (as $\phi$ rises), each firm produces for longer periods for the domestic market. If the size of the latter is small, the domestic firm cannot support the burden of a very high cost in quality, even if it anticipates that it can be the leader once trade is liberalized. This makes it easier for the firm located in the large country to 'leapfrog' the rival and produce a quality which is higher.

Fig. 2 shows the equilibrium outcomes in the plane $(\phi, \mu)$. The equilibrium where the leader comes from the large country (denoted by $E_{1}$ ) always exists, whereas the equilibrium where the leader comes from the small country (denoted by $E_{2}$ ) exists only if trade is liberalized soon enough or if the two countries are not too different in sizes, for the reasons we have given above.

For the values of the parameters such that the equilibrium $E_{2}$ exists, one can then use the values of quality, $u_{1}$ and $u_{2}$, which solve Eqs. (10) and (11) to derive all the other equilibrium values. Fig. 3 illustrates the equilibrium solutions (the dotted line indicates parameter values for which the equilibrium with the small country firm being the leader does not exist). As in the previous case, the results can be understood by thinking in terms of the competition and the market size effects. A complete discussion is probably superfluous. It may be worth emphasizing that when the firm from the large country is to be the bottom quality firm, then its profits are certainly going to shrink as the date of liberalization is anticipated. Since it comes from the large country and it produces the low

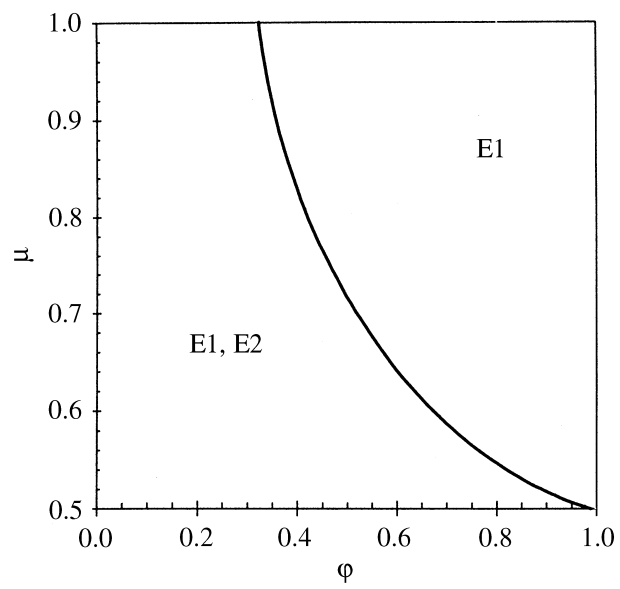

Fig. 2. Existence of equilibria ( $E_{1}$ : leader from large country; $E_{2}$ : leader from small country). $\varphi=$ timing of trade liberalization; $\varphi=0$, immediate liberalization; $\varphi=1$, autarky forever. 

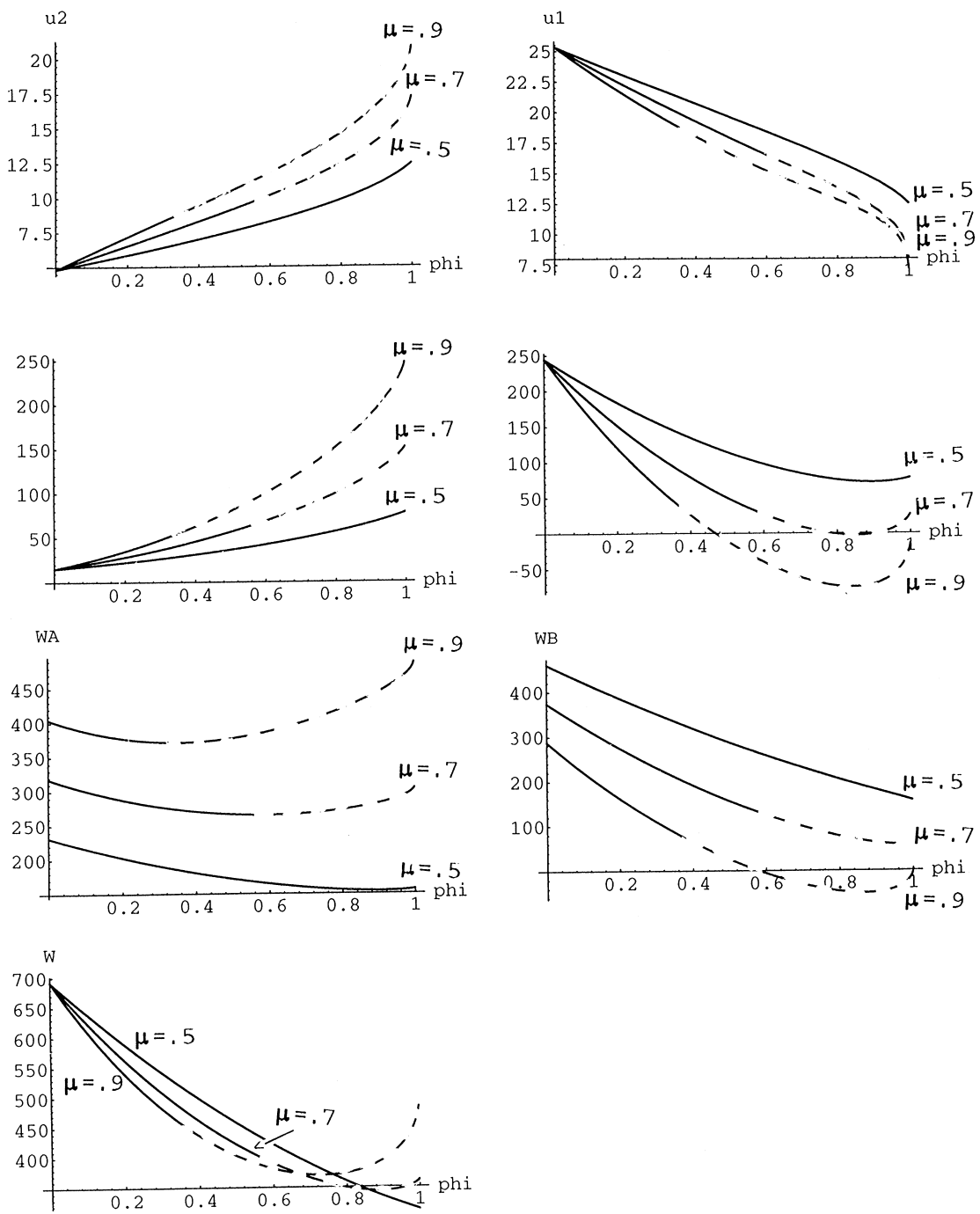

Fig. 3. Market leader in the small country. Equilibrium qualities, profits and welfares. $\phi=$ timing of trade liberalization; $\phi=0$, immediate liberalization; $\phi=1$, autarky forever.

quality at the open markets equilibrium, the competition effect is always dominant (the additional market when trade opens is relatively unimportant with respect to the effect played by the opening of competition). The opposite is true for the small country firm, which benefits both from the expansion of the market and from being the leader. 
Even in this case, welfare attains its maximum level in both countries when trade liberalization occurs from the outset $(\phi=0)$. However, similarly to the previous equilibrium case, there might be a welfare loss in the case of a delay in the liberalization process. In particular, this occurs for a large country whose firm is relegated to the production of a low quality (see the schedule $W_{\mathrm{A}}$ when $\mu=0.5$ ), and when trade is liberalized only at a late period ( $\phi$ is close to 1 ). Here again, consumers do not enjoy free trade of goods for a long enough period to outweigh the firm's losses with respect to autarky.

By comparing the values under the two different equilibrium configurations (Figs. 1 and 3), it can be checked that the domestic welfare in each country is higher when the national firm is the market leader, which suggests that a government would have an incentive to commit to help the domestic firm to gain such a position. Total welfare is higher when the market leader is located in the large country. This is quite intuitive a result, since it is more efficient to have an equilibrium where the top quality firm spreads its investment costs over a larger domestic market. Although our analysis suggests a welfare improving role for free trade, the reader should be aware that gains from trade do not necessarily arise in any vertical product differentiation models. In the papers by Shaked and Sutton (1984) and Motta (1992) a country's welfare might decrease following a trade liberalization process. This different outcome deserves an explanation. In those models, the possible adverse effect of trade mainly depends on the fact that the so-called 'finiteness property' holds there. As market size increases, a larger number of firms cannot coexist in the industry. Hence, when trade opens (that is, as the size of the market rises), some of the firms formerly operating in autarky have to exit the industry. Since some firms disappear at the trade equilibrium, free trade can have a dramatic impact as the loss in firms' revenues can outweigh consumers' gains. In our model instead, the finiteness property does not hold and trade liberalization has a less dramatic impact on firms' profits, and hence on countries' welfare.

\subsection{Risk dominance}

It has been shown in Fig. 2 that the game has two strict Nash equilibria, for a region of the parameters $\phi$ and $\mu$. One of the few solution concepts that selects between equilibria in our game, ${ }^{16}$ is the criterion of risk dominance introduced by Harsanyi and Selten (1988). Since the concept of risk dominance is defined only for games with finitely many pure strategies we have to discretize the

\footnotetext{
${ }^{16}$ Standard refinements like perfectness, properness, or strategic stability do not select among strict Nash equilibria. Also, in this game there are no symmetric equilibria and no equilibrium Pareto dominates the other (taking in to account only the welfare of the players, the firms; and not the consumers).
} 
strategy space. We will show the results obtained when the discretization is very coarse, keeping only the equilibrium strategies for the two players. ${ }^{17}$

Risk dominance selects equilibria by comparing the 'riskiness' of equilibrium points. This criterion compares the product of equilibrium misforecasts and the equilibrium with the largest product is the one that risk dominates. Let a $2 \times 2$ game with the following payoff matrix:

\begin{tabular}{c|c|c} 
& $B_{1}$ & $B_{2}$ \\
\hline$A_{1}$ & $a_{11}, b_{11}$ & $a_{12}, b_{12}$ \\
\hline$A_{2}$ & $a_{21}, b_{21}$ & $a_{22}, b_{22}$
\end{tabular}

where the payoffs are such that $E_{1}=\left(A_{1}, B_{1}\right)$ and $E_{2}=\left(A_{2}, B_{2}\right)$ are strict Nash equilibria, and let $L A_{1}=a_{11}-a_{21}$. $L A_{1}$ is the gain made by player $\mathrm{A}$ by predicting rightly that the other player will play $E_{1}$ (and best responding to the prediction) instead of predicting wrongly that the other player will play $E_{2}$ (and best responding to the prediction). Similarly, let $L B_{1}=b_{11}-b_{12}$. $L A_{2}=a_{22}-a_{12} \cdot L B_{2}=b_{22}-b_{21}$. We say that equilibrium $E_{1}$ risk dominates equilibrium $E_{2}$ when $L A_{1} L B_{1}>L A_{2} L B_{2}$.

Let $E_{1}$ be the equilibrium where the big country firm is the leader and $E_{2}$ be the equilibrium where the small country firm is the leader. Recall that $\mathrm{A}$ is the big country and $\mathrm{B}$ is the small country. In our case $a_{11}=\pi_{1 \mathrm{~A}}\left(u_{1}^{*}, u_{2}^{*}\right)$, $a_{21}=\pi_{1 \mathrm{~A}}\left(u_{1}^{* *}, u_{2}^{*}\right), a_{12}=\pi_{1 \mathrm{~A}}\left(u_{1}^{*}, u_{2}^{* *}\right), a_{22}=\pi_{2 \mathrm{~A}}\left(u_{2}^{* *}, u_{1}^{* *}\right), \quad b_{11}=\pi_{2 \mathrm{~B}}\left(u_{1}^{*}, u_{2}^{*}\right)$, $b_{21}=\pi_{2 \mathrm{~B}}\left(u_{1}^{* *}, u_{2}^{*}\right), b_{12}=\pi_{2 \mathrm{~B}}\left(u_{1}^{*}, u_{2}^{* *}\right)$ and $b_{22}=\pi_{1 \mathrm{~B}}\left(u_{2}^{* *}, u_{1}^{* *}\right)$.

It can be shown numerically that $L A_{1} L B_{1} \geq L A_{2} L B_{2},{ }^{18}$ and the equality only holds when $\phi=0$, that is, when liberalization occurs at the earliest possible date. Thus, for the game we are studying, the risk dominance criterion selects the equilibrium where the leader is the large country firm, except in the limiting case where the two countries liberalize the markets immediately (when $\phi=0$ ).

\section{Transport costs, and other extensions}

In this section, we relax some of the assumptions we have made so far. We deal with positive transport costs, differences in tastes across the two countries, different costs and different liberalization dates.

${ }^{17}$ The restriction does not condition the results, anyway. We have done numerical analysis (available upon request), using the 'tracing procedure' of Harsanyi and Selten (1988), that shows that the risk dominant equilibrium is the same even for a much finer discretization.

${ }^{18}$ Details available from the authors. 


\subsection{Transport costs}

Transport costs give a further advantage to the large country firm, which enjoys a larger captive market. Relative to the benchmark case, the existence of transportation costs reduces the profitability of the small country firm, and this limits its incentive to invest in quality. It will be more difficult for this firm to be the leader at equilibrium. With transport costs the area where the small country firm can be the leader at equilibrium $\left(E_{2}\right)$ is reduced with respect to the case of no transport costs. ${ }^{19}$

Note also that while in the benchmark case (zero transport costs) the equilibrium with the firm from the small country being the leader will always exist if trade liberalization is immediate $(\phi=0)$, this is no longer true in the case of transport costs. This is because the large country firm will enjoy the advantage of a larger domestic market even if trade occurs from the first period. For large enough transport costs and large enough country differences, equilibrium $E_{2}$ does not exist even if trade occurs at the very beginning of the game.

\subsection{Different preferences for quality, or incomes}

We have so far assumed that consumers in the two countries have identical average propensity to pay (or taste) for quality $\left(\bar{\theta}_{\mathrm{A}}=\bar{\theta}_{\mathrm{B}}=\bar{\theta}\right)$. Since in our model a relationship can be established between taste for quality and income (see Tirole, 1988, p. 86), we may interpret the case treated so far as one where countries have similar per-capita income but different population size. If trade occurs between countries of similar population size but different percapita incomes, that is $\bar{\theta}_{\mathrm{A}} \geq \bar{\theta}_{\mathrm{B}}$ and $S_{\mathrm{A}}=S_{\mathrm{B}}$, it is straightforward to see from the profit expressions that results would not change, since country A firm still enjoys a larger domestic market. This explains why in the paper we refer to country A indifferently as the rich or the large country.

When $S_{\mathrm{A}} \geq S_{\mathrm{B}}$ but $\bar{\theta}_{\mathrm{A}} \leq \bar{\theta}_{\mathrm{B}}$ two forces of opposite sign are at work. The former enlarges the relative size of market $A$, whereas the latter reduces it. In particular, country A will have the larger domestic market if $S_{\mathrm{A}} \bar{\theta}_{\mathrm{A}}^{2} \geq S_{\mathrm{B}} \bar{\theta}_{\mathrm{B}}^{2}$. If this condition holds, we can still speak of country A's firm as the one located in the large country, and all the results and discussions above will still hold.

\subsection{Asymmetries in costs}

Consider first asymmetry in production costs. If the large country has also a production cost advantage (for instance, because of cheaper labor), this

\footnotetext{
${ }^{19}$ In other words, the locus which separates the regions $\left(E_{1}\right)$ and $\left(E_{1}, E_{2}\right)$ in Fig. 2 would shift to the left. See Appendix A.1 for the formal analysis.
} 
strengthens the previous results. Since both asymmetries increase its profitability and incentive to invest in quality, country A firm's chances to be the market leader at equilibrium are higher. The case where the small country firm has a production cost advantage is less trivial. The market scale effect helps the large country firm, whereas the production cost effect favors the small country firm. It can be shown (see the appendix for a formal argument) that if the cost advantage is high enough, there is a unique equilibrium where the small country firm is the leader.

Fig. 4 represents this effect in the same space $(\phi, \mu)$ as Fig. 2. Lower production costs in country $\mathrm{A}\left(e_{\mathrm{A}}=0.7\right)$ relative to country $\mathrm{B}\left(e_{\mathrm{B}}=1\right)$ implies that the area where only the equilibrium with the large country firm being the leader $\left(E_{1}\right)$ exists shrinks relative to the case of identical production costs. There also exists a region where this equilibrium disappears altogether (see Appendix A.2 for a formalization).

Consider now the case of identical production costs but different costs of developing the quality of products. We have so far assumed that the parameter $k$ in the quality improvement function is identical for both firms $\left(k_{\mathrm{A}}=k_{\mathrm{B}}=k\right)$. If differences in $R \& D$ or advertising technologies were in favor of country $A$, these would reinforce the country size advantage, and the results would be strengthened. The interesting case is therefore the one where the firm from the small country $\mathrm{B}$ is more efficient in introducing innovations and improving quality, so that $k_{\mathrm{A}} \geq k_{\mathrm{B}}$. This case is very similar to the one just discussed where firms have identical quality costs but different production costs (see Appendix A.2). If the firm coming from the small country has an advantage in quality

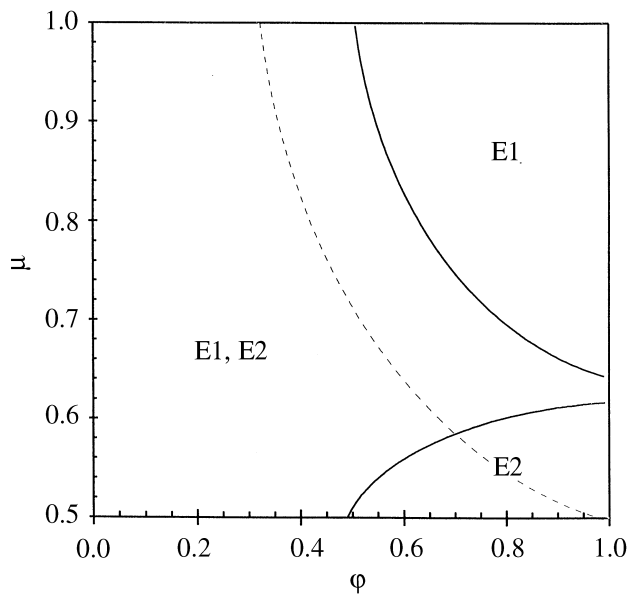

Fig. 4. Existence of equilibria, under productive cost advantage of country $\mathrm{B}\left(e_{\mathrm{A}}=0.7 ; e_{\mathrm{B}}=1\right) . \varphi=$ timing of trade liberalization; $\varphi=0$, immediate liberalization; $\varphi=1$, autarky forever. 
development costs, this might outweigh its market size disadvantage. The stronger its cost advantage, the earlier trade liberalization and the less unequal country sizes, the more likely it is that country B's firm will be the leader at the equilibrium.

\subsection{Different dates of market opening}

Although optimistic as for the welfare effects on each country as a whole, our model also shows that trade liberalization might relegate a firm coming from poorer, smaller or less technologically advanced countries to production of lower quality products. To compensate for existing asymmetries, different opening periods for the different markets might be chosen. For instance, if market $\mathrm{A}$ opens to imports from country $\mathrm{B}$ at a period $K_{\mathrm{A}}$ : while (the smaller) market $\mathrm{B}$ opens to trade at a later period $K_{\mathrm{B}}>K_{\mathrm{A}}$, the two firms' profits are $\pi_{\mathrm{A}}=\phi_{\mathrm{A}} \Pi_{\mathrm{A}}^{\mathrm{M}}+\left(1-\phi_{\mathrm{A}}\right) \Pi_{\mathrm{A}}^{\mathrm{D}}-F, \quad$ and $\pi_{\mathrm{B}}=\phi_{\mathrm{A}} \Pi_{\mathrm{B}}^{\mathrm{M}}+\left(\phi_{\mathrm{B}}-\phi_{\mathrm{A}}\right) \Pi_{\mathrm{B}}^{\mathrm{M}}+$ $\left(1-\phi_{\mathrm{A}}\right) \Pi_{\mathrm{B}}^{\mathrm{D}}-F$, where $\phi_{\mathrm{A}}$ and $\phi_{\mathrm{B}}$ indicate when trade is liberalized in each country.

The longer $\phi_{\mathrm{B}}$ with respect to $\phi_{\mathrm{A}}$, the stronger the possibility for the small country firm to become the leader, since its marginal profitability of an investment in quality rises. However, a delayed opening date for the small country might not be recommendable in general. First, we know that firms located in a very small country might gain from trade even if they are relegated to production of lower quality goods (see Fig. 1) because of the importance of the market expansion effect. Therefore, there would be no reason to grant them a longer period of protection on their domestic market. Second, from a broader perspective than the one allowed by our formalization, we should consider the possibility of adverse effects of longer protection of a country's firms. Third, the large country government, or its firms, might not accept different opening dates for the two economies.

\section{Conclusions}

Our model underlines that domestic market size plays an important role in determining the success of firms in the international markets. Indeed, both the analysis of the existence of equilibrium outcomes and the use of risk dominance as the criterion for equilibrium selection suggest that a firm coming from a large (or rich) country is the likelier market leader under free trade, unless it suffers from strong cost disadvantages (and transport costs are not large).

Even if each country as a whole gains from trade, trade might decrease firms' profits. In our model (when firms' costs are identical), there is always one firm which loses from trade. If the large country firm is the market leader at the trade equilibrium and size asymmetries are not too strong, the loser is the firm from 
the small country. But when size asymmetries are very strong it is the large country firm which loses from trade, since the (negative) competition effect dominates the (positive) market expansion effect (which would be of a secondorder magnitude for a firm coming from a very large country but not for a firm coming from a very small country). If the small country firm is the leader after trade is opened, then it is the large country firm which always loses from trade. This is the result of having to sell a lower quality product and of a market expansion effect which is not sufficient to outweigh the negative effect of competition. The use of risk dominance as a criterion for equilibrium selection suggests that the case where the leader comes from the small country is less likely to arise in the basic model. However, a strong enough production cost advantage would result in a (unique) equilibrium where the small country firm would be the leader at the international trade equilibrium. We consider the analysis carried out here as a step towards a better identification of the forces which hurt (or benefit) firms under processes of trade liberalization. We feel this is a necessary step to understand the conditions under which firms oppose (or favor) such processes.

\section{Acknowledgements}

This paper is a thoroughly revised version of a paper appeared as CEPR Discussion Paper No. 1326 (February 1996), London. We have benefited from comments made by participants in seminars at Universidad del País Vasco (Bilbao), London Business School, IIES (Stockholm), Universitat Pompeu Fabra, ERWIT 1995 (Thessaloniki), London School of Economics and Oxford University, and especially by Raquel Fernandez, Elhanan Helpman, Henrik Horn, Jorge Padilla, Alasdair Smith, Konrad Stahl. We are particularly grateful to Jim Markusen for comments and discussions on a previous draft. Thanks are also due to the editor, Xavier Vives, and two referees. Partial financial support from the CEPR - MIRAGE program (Motta) and the Spanish Ministry of Education through DGYCIT grant PB96-0302 (Cabrales) and PB94-0663 (Motta) are also gratefully acknowledged.

\section{Appendix}

\section{A.1. Transport costs}

We introduce transport costs, modeled as 'iceberg costs'. When a firm ships abroad a number $q$ of units of the good, only $q / g$ (with $g \geq 1$ ) units arrive at destination in the foreign market. Therefore, foreign sales give the exporting firm a unit revenue of $p / g$ which is lower than the price $p$ paid by foreign consumers. 
Monopoly profits for the firms are obviously unchanged, while duopoly profits for the top and the bottom quality firms with positive transport costs are (for $i, j=\mathrm{A}, \mathrm{B} ; i \neq j ; g \geq 1)^{20}$

$$
\begin{aligned}
& \pi_{1 j}^{\mathrm{D}}=p_{1}\left(\bar{\theta}-\frac{p_{1}-p_{2}}{u_{1}-u_{2}}\right)\left(S_{j}+\frac{S_{i}}{g}\right), \\
& \pi_{2 i}^{\mathrm{D}}=p_{2}\left(\frac{p_{1}-p_{2}}{u_{1}-u_{2}}-\frac{p_{2}}{u_{2}}\right)\left(S_{i}+\frac{S_{j}}{g}\right) .
\end{aligned}
$$

We can now solve the price stage of the game. Intertemporal profits are

$$
\begin{gathered}
\pi_{1 j}=\frac{\phi S_{j} u_{1} \bar{\theta}^{2}}{4}+\frac{4(1-\phi) u_{1}^{2}\left(u_{1}-u_{2}\right)\left(S_{j}+S_{i} / g\right) \bar{\theta}^{2}}{\left(4 u_{1}-u_{2}\right)^{2}}-\frac{k u_{1}^{2}}{2}, \\
\pi_{2 i}=\frac{\phi S_{i} u_{2} \bar{\theta}^{2}}{4}+\frac{(1-\phi) u_{1} u_{2}\left(u_{1}-u_{2}\right)\left(S_{i}+S_{j} / g\right) \bar{\theta}^{2}}{\left(4 u_{1}-u_{2}\right)^{2}}-\frac{k u_{2}^{2}}{2}, \\
i, j=\mathrm{A}, \mathrm{B} ; i \neq j ; g \geq 1 .
\end{gathered}
$$

By comparing the expressions above with expressions (5) and (6), one can see that transport costs reduce the relative profitability of the small country firm. Duopoly profits are now multiplied by $\left(S_{\mathrm{A}}+S_{\mathrm{B}} / g\right)$ for the firm located in the large country $\mathrm{A}$, and by $\left(S_{\mathrm{B}}+S_{\mathrm{A}} / g\right)$ for country B firm, while both were multiplied by $\left(S_{\mathrm{A}}+S_{\mathrm{B}}\right)$ in expressions (5) and (6) with no transport costs. Given that $S_{\mathrm{A}} \geq S_{\mathrm{B}}$ and $g \geq 1$, it follows that $\left(S_{\mathrm{A}}+S_{\mathrm{B}} / g\right) \geq\left(S_{\mathrm{B}}+S_{\mathrm{A}} / g\right)$.

\section{A.2. Asymmetries in costs}

Assume that the production of a given good requires some units of that same good, with the same level of quality $u_{i}$, as an input in the production process (think of farmers using seeds or computer manufacturers using computers). The more inefficient is the firm (the higher its production costs), the fewer the units of the good which are obtained as a final output from any given number of initial units of the good.

Let us write gross profits of firm $i$ as $\Pi_{i}=p_{i} e_{i} q_{i}$, where $e_{i}$ is the efficiency parameter, or an inverse measure of production costs (with $1 \geq e_{i} \geq 0$ ) and where $p_{i}$ and $q_{i}$ are as usual the price and output of firm $i$. The parameter $e_{i}$ acts simply as a rescaling factor on both duopoly and monopoly profits and we can

\footnotetext{
${ }^{20}$ Note that even when transport costs are positive, equilibrium prices do not depend on the assumption of segmented vs. integrated markets. This is because transport costs affect only market sizes, which in turn do not affect first-order conditions at the price stage of the game.
} 
write the intertemporal profit functions of the firms in the presence of production costs as

$$
\begin{aligned}
& \pi_{1 j}= \frac{\phi e_{j} S_{j} u_{1} \bar{\theta}^{2}}{4}+\frac{4(1-\phi) u_{1}^{2}\left(u_{1}-u_{2}\right) e_{j} S \bar{\theta}^{2}}{\left(4 u_{1}-u_{2}\right)^{2}}-\frac{k u_{1}^{2}}{2} \\
& \pi_{2 i}= \frac{\phi e_{i} S_{i} u_{2} \bar{\theta}^{2}}{4}+\frac{(1-\phi) u_{1} u_{2}\left(u_{1}-u_{2}\right) e_{i} S \bar{\theta}^{2}}{\left(4 u_{1}-u_{2}\right)^{2}}-\frac{k u_{2}^{2}}{2}, \\
& i, j=\mathrm{A}, \mathrm{B} ; i \neq j .
\end{aligned}
$$

Without loss of generality we fix $e_{\mathrm{B}}=1 \geq e_{\mathrm{A}}$. The effect of higher unit costs in country A is to increase (decrease) the range of parameter values for which the equilibrium with the small (large) country firm being the leader exists. We can have three possible situations, as discussed in Section 4.3. If size asymmetries are large and cost asymmetries are small, we find only the equilibrium of type $E_{1}$ (leader in the large country); for low enough size and cost asymmetries both equilibria exist; finally, for low enough size asymmetries and large enough cost asymmetries, only the type $E_{2}$ equilibrium (leader in the small country) exists. ${ }^{21}$

The case of different costs of quality is formally identical to the case of different production costs. The reason is that the parameter $k_{i}$ enters multiplicatively the cost expression in the intertemporal profit function, while $e_{i}$ enters multiplicatively the gross profit term in the same function (recall that $\left.\pi_{i}=e_{i} \Pi_{i}^{\mathrm{M}}\left(u_{i}\right)+e_{i} \Pi_{i}^{\mathrm{D}}\left(u_{i}, u_{j}\right)-k_{i} G\left(u_{i}\right)\right)$. As a result, a higher $k_{i}$ affects equilibrium solutions in qualitatively the same way as a lower $e_{i}$, all other things being equal. Hence, the discussion made for the case of different unit costs still holds for the case of different quality costs.

\section{References}

Anderson, S.P., Donsimoni, M.P., Gabszewicz, J.J., 1989. Is international trade profitable to oligopolistic industries? International Economic Review 30, 725-733.

Cabrales, A., García-Fontes, W., Motta, M., 2000. Risk dominance selects the leader. An experimental analysis. International Journal of Industrial Organization 18, 137-162.

Cordella, T., 1993. Trade liberalization and oligopolistic industries: A welfare appraisal. Recherches Economiques de Louvain 59, 355-363.

${ }^{21}$ This occurs when $\phi$ is close to 1 and countries are not so different ( $\mu$ close to 0.5 ). To understand why this happens, consider the extreme case where $\phi=1-\varepsilon$ and $\mu=0.5$. In this case, trade opens only at the very last period of the game and equilibrium qualities under liberalization cannot differ much from autarky ones. But since under autarky we have $u_{\mathrm{A}}=\left(e_{\mathrm{A}} / 4\right)(S / 2) \bar{\theta}^{2}<u_{\mathrm{B}}=(1 / 4)(S / 2) \bar{\theta}^{2}$, the former cannot be the top quality at the trade equilibrium. By a continuity argument, one can then explain why in a region where $\phi$ is close to 1 and $\mu$ is close to 0.5 the $E_{1}$ equilibrium does not exist. 
Dinopoulos, E., 1988. A formalization of the biological model of trade in different products. Journal of International Economics 25, 95-110.

Gabszewicz, J.J., Thisse, J.F., 1979. Price competition, quality and income disparities. Journal of Economic Theory 20, 340-359.

Harsanyi, J.C., Selten, R., 1988. A General Theory of Equilibrium Selection in Games. MIT Press, Cambridge, MA.

Krugman, P., 1980. Scale economies, product differentiation and the pattern of trade. American Economic Review 70, 950-959.

Linder, S.B., 1961. An Essay on Trade and Transformation. Wiley, New York.

Markusen, J.R., 1981. Trade and the gains from trade with international competition. Journal of International Economics 11, 531-551.

Motta, M., 1992. Sunk costs and trade liberalisation. Economic Journal 102, 578-587.

Motta, M., 1993. Endogenous quality choice: Price vs. quantity competition. Journal of Industrial Economics 41, 113-131.

Motta, M., Thisse, J.F., Cabrales, A., 1997. On the persistence of leadership and leapfrogging in international trade. International Economic Review 38, 809-824.

Nguyen, T.T., Wigle, R.M., 1992. Trade liberalisation with imperfect competition: The large and the small of it. European Economic Review 36, 17-35.

Porter, M.E., 1990. The Competitive Advantage of Nations. McMillan, London.

Shaked, A., Sutton, J., 1982. Relaxing price competition through product differentiation. Review of Economic Studies 49, 3-13.

Shaked, A., Sutton, J., 1984. Natural oligopolies and international trade. In: Kierzkowski, H. (Ed.), Monopolistic Competition and International Trade. Clarendon, Oxford. 